\title{
BIBLIOGRAFÍA
}

- ALZA C. William R; Salamanca R. Catalina. REVALORIZACION DE LA CACHAZA EN LA INDUSTRIA PANELERA DE LA PAZ (SANTANDER), Volumen $5 \mathrm{~N}^{\circ} 2$ AÑO 2007.

- GARCÍA B Hugo. et. al. Oportunidades de la producción más limpia en la industria panelera. Programa de Procesos Agroindustriales - CORPOICA C.I. TIBAITATA, 2004.

- GARCÍA J. \& A. Rodríguez. Industrias químicas y agroalimentarias. Análisis y ensayos. Alfaomega. México, 2004.

\section{EL NEOLIBERALISMO ¿ENTRÓ EN CRISIS?}

\section{Jullieth Alexandra Barón Bayona Grupo MODEAL}

Los acontecimientos que han marcado la actualidad de la economía mundial, pone en tela de juicio el proyecto neoliberal en los diferentes países, si éste deba seguir siendo la ideología adecuada para manejar la economía.

El neoliberalismo propugna por libertad, pero no la libertad en todos sus significados conocidos, sólo existe uno que se funda y es la "libertad de empresa" ésta tiene implicaciones en el sector productivo, especialmente en la disposición para transar libremente en el mercado, que según el neoliberalismo el estado no debe intervenir; sin embargo, esto no quiere decir que el Estado sea excluido de las operaciones del mercado, sino que intervenga de otra manera, es decir, formando un ambiente óptimo para los negocios, como leyes y normas que beneficien al libre mercado. En síntesis el neoliberalismo (acompañado del sector financiero) es la restauración del poder de clase, y el estado ayuda a este fin además para cumplir este objetivo.

Es el sistema financiero el culpable de la crisis actual, éste siempre ha sido inestable y si no esta regulado se erige como un peligro para sector productivo, el cual es relevante en el proceso de acumulación de capital. Históricamente se ha conocido que el sistema capitalista recorre un ciclo (auge, expansión, crisis, recesión), por lo que se hace raro que los analistas no predijeran esta crisis, graso error que hoy tiene a muchos gobiernos en apuros intentando salvaguardar sus economías. La desregulación y la libertad del mercado que tanto defiende el neoliberalismo queda en entredicho, porque solo el mercado no puede regularse, ya que necesitará del Estado para que lo saque de sus propias contradicciones y perjuicios. 
Por otra parte, la expansión del crédito en los Estados Unidos durante los años 2002-2006 a las personas con poca capacidad de pago, resultó un atractivo negocio para los inversionistas de alto riesgo, puesto que presentaba grandes rendimientos, ese dinero que fue para especulación se fue a un hoyo negro, lo que produjo un descontrol generado por el sector financiero que conllevó a un caos en el sector real.

Aquí tenemos que ser cuidadosos, porque el neoliberalismo en la práctica resulta muy distinto al de la teoría, puesto que la libertad de empresa que defiende éste, se encuentra restringida por las barreras de entrada que imponen otras empresas. Actualmente, vemos que la crisis ha servido para que las empresas más poderosas continúen el ascenso, mientras que las pequeñas tienen que enfrentarse a la reestructuración para poder seguir en la competencia o sencillamente abandonar el mercado. Es como si a los promotores del neoliberalismo les gustara estar en procesos de crisis, para poder eliminar el capital que no sirve, menos eficiente y dejar a los más rentables.

En otro sentido, la subida de los precios de los alimentos y del petróleo en el 2008 y luego la disminución presentada de éstos, es una consecuencia del mal funcionamiento del neoliberalismo y de las políticas económicas mal elaboradas para el beneficio de unos pocos, debido a que se genera un aumento de la acumulación del capital, Como dice Stiglitz "los especuladores afirman no ser los causantes del problema, sino que se limitan a practicar el descubrimiento de los precios o, dicho de otro modo el descubrimiento de la escasez", pero vemos en la realidad que eso es una vil mentira, ya que a los especuladores, generalmente les importa sacar beneficios de sus negocios, y los prejuicios no hacen parte de su interés.

Lo que queda es preguntarnos ¿cuánto va hacer el costo que nosotros los consumidores, debemos asumir para rescatar a los que tuvieron unas malas decisiones en el sector financiero? Sólo termino con una frase que pronuncia Stigliz "que mundo tan peculiar, en el que los países pobres se encuentran, de hecho, subvencionando a los mas ricos"

\section{A manera de conclusión:}

La crisis económica mundial, ha evidenciado un fracaso, en cierto modo, del neoliberalismo, pero no en su totalidad, solamente se comprueba que el modelo neoliberal en la práctica no se cumple del todo $y_{r}$ por lo tanto el Estado acude como redentor hacia el mercado para que éste no deje de funcionar; por otra, parte ef neoliberalismo en crisis logra cumplir su objetivo que es el de privilegiar a los capitales mas avanzados y eliminar a los mas ineficientes, por lo que se consolida el poder de clase. 


\title{
BIBLIOGRAFÍA
}

- David Harvey. Breve historia del neoliberalismo.

- JUAN PABLO MATEO TOMÉ. Crisis, política monetaria y tipos de interés: fuente del neoliberalismo y la financiación.

- Joseph E. Stiglitz. ¿El fin del neoliberalismo?

\section{DINÁMICA MOLECULAR COMO TÉCNICA DE SIMULACIÓN}

\author{
Lorena Paola Cárdenas Espinosa \\ Grupo de Física Teórica y Computacional
}

\section{Resumen}

Para simular sistemas físicos compuestos por muchas partículas existen diversos métodos matemáticos, cada uno con ciertas ventajas y desventajas, siendo unos más eficientes que otros; cuando exigimos que el método sea de bajo requerimiento computacional sin que deje de ser eficiente, aparece la Dinámica Molecular como un método capaz de reproducir de la mejor manera cualquier modelo físico. En este trabajo se hace una breve descripción de éste método.

\section{INTRODUCCIÓN}

La Dinámica Molecular es un método computacional muy sencillo y eficiente, capaz de reproducir de manera muy aproximada, el comportamiento de un sistema físico donde participen gran cantidad de partículas. Puede utilizarse cualquier lenguaje de programación y un computador sin características especiales. Sin embargo, para tener mejores resultados se requiere la introducción de muchas más partículas, siendo necesario un computador con mucha más velocidad que capacidad de almacenamiento. Para aplicaciones mucho más sofisticadas se utiliza procesamiento en paralelo en computadores ultrarápidos.

\section{DİNÁMICA MOLECULAR}

La Dinámica Molecular (DM) (en ingles Molecular Dynamics) es una técnica de cómputo que permite describir la evolución en el tiempo de un sistema físico partiendo de las causas que hacen que el sistema cambie sus propiedades a lo largo del tiempo.

En general, los sistemas moleculares son complejos y consisten de un gran 